J. Lake Sci. (湖泊科学), 2018, 30(3): 680-692

DOI 10. 18307/2018. 0310

(c) 2018 by Journal of Lake Sciences

\title{
巴丹吉林沙漠湖泊水离子空间复杂性分析”
}

\author{
赵军峰 ${ }^{1,2}$, 李勋贵 ${ }^{1,2 * *}$ \\ (1: 兰州大学资源环境学院西部环境教育部重点实验室, 兰州 730000) \\ (2: 兰州大学干旱区与沙漠研究中心, 兰州 730000)
}

\begin{abstract}
摘 要: 为探讨巴丹吉林沙漠湖泊水离子的空间复杂性, 本文采用滑动样本熵方法, 将沙漠东南部 115 个湖泊的 313 组 采样点分为两组 (2009 年 9 月和 2010 年 9 月为一组, 2011 年 4 月、2012 年 4 月、2013 年 4 月和 2016 年 4 月为一组),并计 算采样点水化学离子的样本熵,分析其空间变化规律. 结果表明,4 月各个离子和 TDS 的空间复杂度大于 9 月; 4 月和 9 月 TDS 熵值和 $\mathrm{Na}^{+} 、 \mathrm{Cl}^{-} 、 \mathrm{~K}^{+}$熵值相关系数较高, TDS 和 $\mathrm{Na}^{+} 、 \mathrm{Cl}^{-} 、 \mathrm{~K}^{+}$在空间上的复杂度变化趋势较为一致, 且 $\mathrm{Na}^{+} 、 \mathrm{Cl}^{-}$、 $\mathrm{K}^{+} 、 \mathrm{CO}_{3}^{2-} 、 \mathrm{HCO}_{3}^{-}$都是在西北部和东南角空间复杂度高, 其他区域复杂度相对较低; $\mathrm{Mg}^{2+}$ 比同期其他离子空间复杂度低, 其在采样 I 区中间部分的复杂度较高; $\mathrm{Mg}^{2+}$ 和 $\mathrm{Ca}^{2+}$ 在 9 月和 4 月空间复杂度相差较大, 9 月 $\mathrm{Ca}^{2+}$ 在采样 I 区西北部有一 个复杂度较高的突变区域; 除 9 月东南角出现较高熵值之外, $\mathrm{SO}_{4}^{2-}$ 空间复杂度分布趋势在 4 月和 9 月基本相同; 对于离 子熵值的季节性变化,气候条件是主导因素; 在同月气候条件相似的情况下,影响可溶性离子熵值空间变化的主要因素 是水源补给; 4 月和 9 月的可溶性离子熵值在研究区中间部分较低,说明该区水源补给量较大.
\end{abstract}

关键词 : 湖泊水离子;空间复杂性;滑动样本熵;巴丹吉林沙漠

\section{Spatial complexity of lake water ions in the Badain Jaran Desert}

\author{
ZHAO Junfeng ${ }^{1,2}$ \& LI Xungui ${ }^{1,2 * *}$ \\ (1: Key Laboratory of Western China's Environmental Systems (Ministry of Education), College of Earth and Environmental \\ Sciences, Lanzhou University, Lanzhou 730000 , P.R.China) \\ (2: Research Center for Arid Region and Desert, Lanzhou University, Lanzhou 730000, P.R. China)
}

\begin{abstract}
In order to investigate and compare the distribution characteristics of the spatial complexity of the lake water ions, the sliding sample entropy and spatial interpolation are employed in this study. The three hundred and thirteen sampling sites in one hundred and fifteen lakes are divided into two groups (one group includes September 2009 and September 2010, another group includes April 2011, April 2012, April 2013 and April 2016) to calculate entropy and analyze spatial complexity. The results show that the spatial complexity of each ion and TDS in April is larger than that in September. The correlation coefficients between the entropy values of TDS and $\mathrm{Na}^{+}, \mathrm{Cl}^{-}$and $\mathrm{K}^{+}$are rather high in both April and September. The variation trend of spatial complexity of TDS is consistent with that of $\mathrm{Na}^{+}, \mathrm{Cl}^{-}$and $\mathrm{K}^{+}$. In September and April, the spatial complexities of $\mathrm{Na}^{+}, \mathrm{Cl}^{-}, \mathrm{K}^{+}, \mathrm{CO}_{3}^{2-}$ and $\mathrm{HCO}_{3}^{-}$are high in the northwest and southeast corner, but low elsewhere. The ion of $\mathrm{Mg}^{2+}$ has less complexity than other ions in the same month, but has higher complexity in the middle part of the sampling Region I. The spatial complexity of $\mathrm{Mg}^{2+}$ and $\mathrm{Ca}^{2+}$ is quite different in September and April. $\mathrm{Ca}^{2+}$ has a mutation high interval of ion complexity in the northwestward of sampling Region $\mathrm{I}$ in September compared with the lows value of ion complexity outside the interval. The spatial complexity trend of $\mathrm{SO}_{4}^{2-}$ is almost the same in April and September; while there is no high values of entropy in the southeast corner. Climate condition is the dominant factor for the seasonal variation of ion's entropy. In the same month with the same climate conditions, the water source recharge is the main factor affecting the spatial variation of entropy of the soluble ions. In April and September, the low entropy values of soluble ions in the middle of the study area indicate that there exists large water supply.
\end{abstract}

Keywords: Lake water ions; spatial complexity; sliding sample entropy; Badain Jaran Desert

* 国家自然科学基金项目 (41530745,51679115) 和兰州大学中央高校基本科研业务费专项 ( lzujbky-2016-173) 联合 资助. 2017-09-06 收稿;2017-09-16 收修改稿. 赵军峰(1989 ), 男, 硕士;E-mail: zhaojf15@ lzu.edu.cn.

** 通信作者;E-mail: lixungui@163.com. 
巴丹吉林沙漠地处中国西北部的阿拉善高原, 气候极其干旱 ${ }^{[1]}$. 沙漠里的高大沙山及其间分布的大量 湖泊这一独特景观引起了众多学者的关注, 他们就高大沙山和湖泊的成因 ${ }^{[2-12]}$ 以及湖泊水的来源 ${ }^{[4,9,13-25]}$ 等 问题进行了大量深人研究, 并取得一系列重要成果. 但随着近 50 年来巴丹吉林沙漠周边地区年平均气温以 $0.4^{\circ} \mathrm{C} / 10 \mathrm{a}$ 的速率明显上升 ${ }^{[26]}$, 以及近十多年来巴丹吉林沙漠地下水的不断减少 ${ }^{[13,27]}$, 已严重威胁到了沙 漠湖泊的存在, 导致湖泊水化学的变化特性愈加复杂. 但湖泊水离子浓度的时空变化规律及其复杂性、影响 因素仍不清楚, 这不利于揭示沙漠湖泊水离子复杂特性. 由于受多种因素 (太阳辐射、温度、补给源和降水 等) 的影响, 沙漠湖泊水离子浓度的空间分布及其变化规律十分复杂, 并非简单的线性关系. 湖泊水离子复 杂性作为湖泊系统的内在特性, 通过对复杂系统进行定量描述, 对揭示湖泊系统内在规律和演变过程具有 重要意义. 因此, 开展湖泊水离子空间复杂性研究具有重要的科学意义和学术价值. 样本熵作为一种度量系 统复杂性的分析方法,已广泛应用于生命科学、水文、工程等领域 ${ }^{[28-31]}$, 为许多学科复杂性问题的分析提供 了一种新的测度方法. 借助于样本商及其滑动窗, 不仅能分析序列复杂度的变化趋势, 还能很好地检测出序 列突变. 因此, 本研究利用样本熵及其滑动窗相结合的方法对巴丹吉林沙漠湖泊水离子的空间复杂性进行 研究, 揭示湖泊水离子的空间分布规律, 同时对影响其空间分布的原因进行分析, 判断摘值空间分布和湖泊 水补给的关系, 为比较有争议的湖泊水补给问题提供一定的参考, 拓宽巴丹吉林沙漠湖泊水补给来源的研 究思路.

\section{1 研究区概况}

巴丹吉林沙漠 $\left(39^{\circ} 20^{\prime} \sim 41^{\circ} 30^{\prime} \mathrm{N}, 99^{\circ} 48^{\prime} \sim 104^{\circ} 14^{\prime} \mathrm{E}\right)$ 位于内蒙古自治区西部, 地处拐子湖和古居延泽以 南、北大山和阿拉善右旗以北、古日乃湖和黑河以东、雅布赖山和腾格里沙漠西北、合黎山和河西走廊东北, 地势西北低、东南高, 面积约为 $5.2 \times 10^{4} \mathrm{~km}^{2}$, 为我国第二大沙漠 ${ }^{[32]}$. 其主要特点是内部有许多高大的沙山和 湖泊, 高大沙山以复型链状居多 ${ }^{[16]}$, 其相对高度大于 $300 \mathrm{~m}$, 最高接近 $500 \mathrm{~m}$, 是世界上最高的沙山 ${ }^{[33]}$. 该区 域气候为典型的大陆气候 ${ }^{[34]}$, 常年盛行西风和西北风, 降水量小于蒸发量, 年降水总量往往取决于某个季节 的集中降水 ${ }^{[35]}$. 巴丹吉林湖泊群区存在一条 $10 \mathrm{~km}$ 宽的无湖风蚀带, 将湖泊分为南北两个带. 沙漠中的湖泊 大多是咸水湖, 只有沙漠东南缘的少数几个湖泊为淡水湖. 沙漠腹部湖泊群区地下水主要储存在更新统湖 积砂层中, 第三系泥质碎屑岩构成隔水底板, 湖积亚砂土亚黏土组成隔水顶板; 南部湖泊区巴丹海子一带由 凹凸不平的白严系碎屑岩为隔水底板, 由全新统湖积沙层、亚砂土与风积沙层构成含水层, 水位埋深 1 $2 \mathrm{~m}^{[36]}$.

本研究的采样区位于巴丹吉林沙漠东南部, 沙漠中绝大部分湖泊位于该区域内, 采样区边界根据采样 点处各离子和总溶解固体 (TDS) 熵值空间插值的最小公共边界确定, 采样区分为 I 区和 II 区, 面积分别为 3498 和 $224.3 \mathrm{~km}^{2}$ (下文全称为采样 I 区和采样 II 区). 采样点共涉及 115 个湖泊, 时间跨度为 2009 年 9 月一 2016 年 4 月, 空间上涵盖了巴丹吉林沙漠大部分湖泊. 此次湖泊边界根据 Landsat8 遥感数据进行绘制, 条带 号为 132 和 133 , 行编号为 32 和 33 , 时间都是 2017 年 3 月, 云量都小于 $2 \%$, 图像经过辐射定标和大气校正 处理. 由于有些采样点所在的湖泊已经干涸, 按 $10 \mathrm{~m}$ 半径的坑洼地处理, 115 个湖泊的面积共 $20.59 \mathrm{~km}^{2}$ (研 究区没有采样点的湖泊和绿洲不包括在内). 采样区和采样点分布见图 1 .

\section{2 材料和方法}

\section{1 水样与离子测定}

除 2016 年数据外,其他数据来源于兰州大学巴丹吉林沙漠野外科学观测实验站. 课题组成员 2009 年 9 月- 2016 年 4 月共从巴丹吉林沙漠腹地 115 个湖泊中采集 313 组水样, 其中 2009 年 9 月、2010 年 9 月和 2013 年 4 月数据已经公开发表, 2016 年 4 月数据为本次新测得的数据. 采样点在研究区内分布尽可能广泛, 空间上尽量均匀,这样进行空间插值时可将湖泊地理位置的影响降低到最小, 具体为: 2009 年 9 月从 43 个 湖泊中采集 45 组水样、 2010 年 9 月从 87 个湖泊中采集 98 组水样、2011 年 4 月从 86 个湖泊中采集 101 组 水样、 2012 年 4 月从 19 个湖泊中采集 19 组水样、 2013 年 4 月从 32 个湖泊中采集 32 组水样、 2016 年 4 月从 7 个湖泊中采集 18 组水样. 采样前先用 $10 \%$ 的盐酸或硝酸将采样瓶进行浸泡洗涤, 再用去离子水冲洗, 采样 


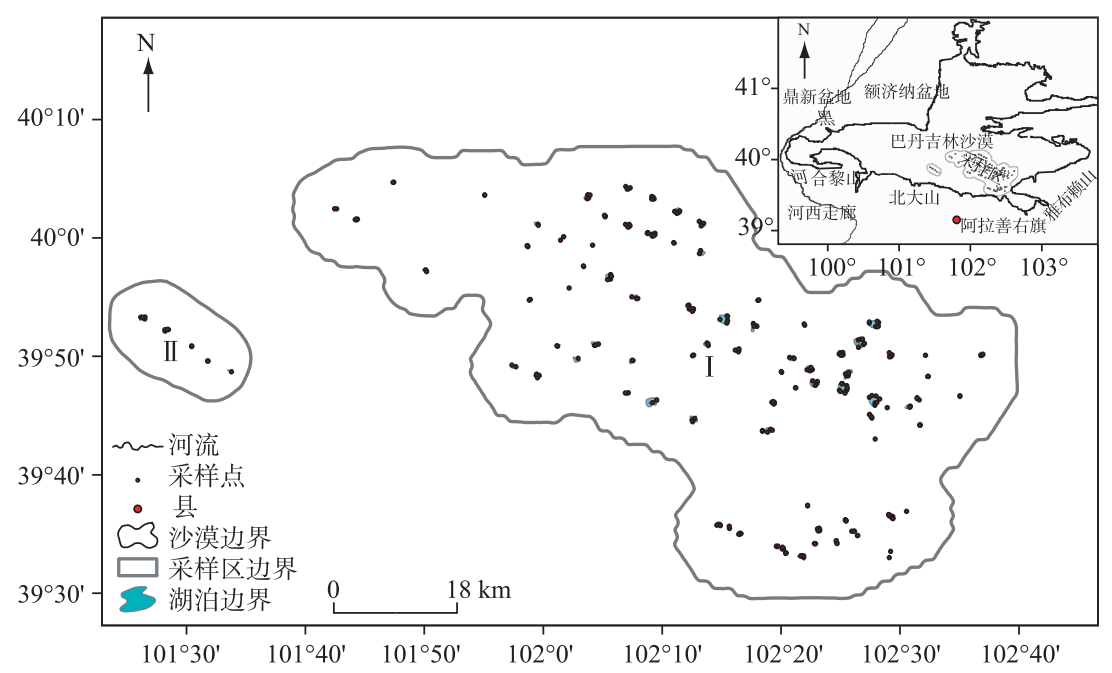

图 1 巴丹吉林沙漠研究区和采样点分布

Fig.1 Study area and distribution of sampling sites in the Badain Jaran Desert

时, 样品瓶都用原水样冲洗 3 次以上,水下密封后取出.

水样中 $\mathrm{Na}^{+} 、 \mathrm{~K}^{+} 、 \mathrm{Ca}^{2+} 、 \mathrm{Mg}^{2+} 、 \mathrm{Cl}^{-} 、 \mathrm{SO}_{4}^{2-}$ 的测定在兰州大学西部环境教育部重点实验室和兰州大学化学化 工学院测试中心完成, 所使用的仪器为美国戴安公司生产的 ICS-2500 和 ICS-1500 型离子色谱仪. 除 2010 年 样品测定使用的是 ICS-1500 型离子色谱仪以外, 其他年份样品都使用 ICS-2500 色谱仪测定. 为保证仪器在 良好的状态下工作, 在测定之前根据水体的电导率, 对水体进行稀释. 为保证测定的精度, 在测定前提前一 天将机器运行, 保证其稳定工作后再进行测定. 另外, 为了减少水中杂质的影响, 将稀释溶液经 $0.45 \mu \mathrm{m}$ 的 滤膜过滤, 并保存于洗净且用过滤后稀释溶液冲洗的 $7 \mathrm{ml}$ 离心管中, 每个保存两份, 并进行密封, 以防止样 品污染. 在进样时, 再次用 $0.45 \mu \mathrm{m}$ 的滤膜过滤. 水中的 $\mathrm{CO}_{3}^{2-}$ 和 $\mathrm{HCO}_{3}^{-}$采用酸碱滴定的方法进行测定. 测定 结果经过阴阳离子平衡检测, 一般情况下, 总阴阳离子相对误差不大于 $\pm 5 \%$, 但研究区大多数湖泊 TDS 很 高, 很多都稀释 1000 5000 倍, 稀释过程中存在的误差使得最后误差变大. 当盐度很高时, 水离子分析结果 趋向于含有高浓度的少数组份, 在这种情况下, 可信度区间可以定义为 $\pm 15 \%{ }^{[37]}$. 本研究测得的结果都在 $\pm 15 \%$ 之内, 其中有 $89.6 \%$ 的数据相对误差不大于 $\pm 10 \%$, 其余数据相对误差为 $\pm 10 \% \sim \pm 15 \%$.

\section{2 样本熵}

样本熵是 Richman 等 ${ }^{\left[{ }^{30]}\right.}$ 于 2000 年提出来的一种有别于近似熵的不计人自身匹配量的统计方法, 是对 近似熵的改进. 与近似摘相比, 它具有计算不依赖数据长度、较高的一致性和对缺失数据不敏感等优点 ${ }^{[38]}$. 样本熵表示非线性动力学系统产生新概率模式的大小, 可以定量表示非线性系统的复杂度以及规则度. 样 本熵值越低, 序列自我相似性就越高, 产生新概率的模式就越低, 序列就越简单; 反之亦然. 样本熵的计算步 骤如下 ${ }^{[30]}$ :

(1) 对于长度为 $N$ 的时间序列 $x(i=1,2 、 \cdots, N)$, 定义维数 $m$, 将序列组成一组 $m$ 维矢量:

$$
X(i)=[(x(i), x(i+1), \cdots, x(i+m-1)],(i=1 、 2 、 \cdots 、 N-m+1)
$$

(2) 定义 $m$ 维矢量 $X(i)$ 与 $X(j)$ 之间的距离 $d[X(i), X(j)]$ 为两者对应元素中最大的一个,即:

$$
d[X(i), X(j)]=\max [|X(i+k)-X(j+k)|],(k=1 、 2 、 \cdots, m-1)
$$

对于每一个 $i$, 计算 $X(i)$ 与 $X(j)$ 之间的距离 $d[X(i), X(j)]$.

(3) 给定阈值 $r$, 对每一个 $i$ 值统计 $d[X(i), X(j)]<r$ 的个数 $k$, 计算其与距离总数 $N-m+1$ 的比值, 记作 $C_{i}^{m}(r)$, 即:

$$
C_{i}^{m}(r)=\frac{k}{N-m+1}(i=1,2 、 \cdots, N-m+1)
$$


(4) 计算 $C_{i}^{m}(r)$ 的平均值, 即:

$$
C^{m}(r)=\frac{1}{N-m} \sum_{i=1}^{N-m} C_{i}^{m}(r)
$$

(5) 把维数变成 $m+1$, 重复步骤 $(1) \sim(4)$, 得到 $C^{m+1}(r)$.

(6) 求得样本熵值:

$$
\operatorname{Samp} \operatorname{En}(m, r, N)=\ln \left[C^{m}(r) / C^{m+1}(r)\right]
$$

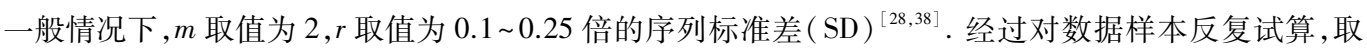
$m=2 、 r=0.2, \mathrm{SD}$ 效果较好.

为了进一步检测水离子随空间的动态变化特征, 采取样本摘及其滑动窗口相结合的方法, 其具体计算 步骤为: (1)选取子序列的长度 $L$; (2) 从数据序列的第 1 个数据开始, 以滑动步长 $H$ 选取子序列长度为 $L$ 的子 序列, 直到选取完所有序列为止; (3)按照公式 (1) (5) 的样本摘计算步骤计算所有序列的样本熵值. 本研究 中取子序列长度 $L$ 为 100 , 滑动步长 $H$ 为 1 , 第 1 个滑动窗口得到的值为第 1 个数据样本的熵值, 以此类推. 当数据序列结束时, 对数据序列进行循环, 直到得到所有样本的熵值.

\section{3 结果与讨论}

\section{1 湖泊水体 TDS 的空间分布规律}

由于不同季节离子浓度变化很大,具有 9 月 $>7$ 月 $>1$ 月 $>4$ 月的特点, 而采样点又全都在 4 月和 9 月这 两离子浓度相差最大的月份, 为了后面进行对比分析, 我们将 2011 年 4 月、2012 年 4 月、 2013 年 4 月和 2016 年 4 月的数据归为一组, 2009 年 9 月和 2010 年 9 月的数据归为一组,简称为 4 月采样点和 9 月采样点 (下 同). 考虑到即使是相同月份的离子数据也可能受年度变化的影响, 且 4 月采样点从 2011 年持续到 2016 年, 跨度较大, 故对离子浓度年度变化影响较大的温度与降水数据进行统计, 数据分别来源于沙漠腹地布设 的气象站和阿拉善右旗气象站. 结果显示 2011、2012 和 2013 年在 4 月的温度与降水分别为 11.19、11.11 和 $11.02^{\circ} \mathrm{C}$ 与 1.9 、 5.0 和 $0 \mathrm{~mm}$, 温度和降水相差都不大. 由于 2016 年 4 月缺少温度和降水数据, 我们对 2016 年 和其他年份相同湖泊采样点的平均 TDS 进行对比, 其 TDS 平均值分别为 130.78 和 $142.5 \mathrm{~g} / \mathrm{L}$, 相差也不太 大. 因此, 认为年际变化的影响较小, 这样分组合理. 研究区内湖泊水化学类型较多, 其分类方法为阴阳离子 毫克当量大于 $5 \%$ 的都参与分类, 但小于 $25 \%$ 的表示在括号中, 离子次序按百分含量由大到小排列. 水化学 类型主要有 $\mathrm{Na}-\mathrm{Cl}-\left(\mathrm{SO}_{4}\right)-\left(\mathrm{CO}_{3}\right) 、 \mathrm{Na}-\mathrm{Cl}-\left(\mathrm{CO}_{3}\right)-\left(\mathrm{SO}_{4}\right) 、 \mathrm{Na}-\mathrm{CO}_{3}-\mathrm{Cl}-\left(\mathrm{SO}_{4}\right) 、 \mathrm{Na}-\mathrm{Cl}-\mathrm{CO}_{3}-\left(\mathrm{SO}_{4}\right) 、 \mathrm{Na}-\mathrm{Cl}-\left(\mathrm{CO}_{3}\right)$ 、 $\mathrm{Na}-\mathrm{Cl}-\mathrm{CO}_{3} 、 \mathrm{Na}-(\mathrm{Mg})-\mathrm{Cl}-\mathrm{SO}_{4} 、 \mathrm{Na}-(\mathrm{Mg})-\mathrm{Cl}-\mathrm{SO}_{4}$ 型, 也有个别属于 $\mathrm{Na}-(\mathrm{Mg})-\mathrm{Cl}_{-} \mathrm{SO}_{4}-\left(\mathrm{CO}_{3}\right)-\left(\mathrm{HCO}_{3}\right) 、 \mathrm{Na}-(\mathrm{Mg})-$ ( Ca) - $\mathrm{Cl}-\mathrm{SO}_{4}-\left(\mathrm{HCO}_{3}\right)$ 等类型. $\mathrm{pH}$ 大部分在 9 11 之间. 为了分析其空间变化规律, 分别对 4 月采样点和 9 月采样点进行普通克里金插值, 采样点分布和插值结果如图 2 所示. 4 月和 9 月采样点的插值误差、均方根 误差、标准均方根误差和平均标准误差分别为 $-1.17 、 72.25 、 1.40 、 58.09$ 和 $-0.23 、 116.42 、 0.90 、 112.64 .4$ 月共 有 170 个采样点 (图 2a), 平均 TDS 为 $120.50 \mathrm{~g} / \mathrm{L}$, 最小值出现在沃斯格图诺尔, 为 $0.86 \mathrm{~g} / \mathrm{L}$, 最大值出现在哈 沙图 (北), 高达 $413.66 \mathrm{~g} / \mathrm{L} .9$ 月共有 143 个采样点 (图 $2 \mathrm{~b}$ ), 其平均 TDS 为 $185.98 \mathrm{~g} / \mathrm{L}$, 最小值出现在沃门 吉林, 为 $0.79 \mathrm{~g} / \mathrm{L}$, 最大值出现在通古图, 高达 $523.44 \mathrm{~g} / \mathrm{L} .4$ 月采样点的平均 TDS 明显小于 9 月. 从图 2 可以 看出 4 月采样点黑色区域面积远小于 9 月, 也就是说 9 月离子浓度高值区域远大于 4 月,这是因为 9 月蒸发 量大, 地下水水位低, 湖泊补给量较少, 导致其 TDS 不断升高, 而 4 月蒸发量相对较小, 地下水水位高, 湖泊 补给量相对较多, 补给水分对湖泊 TDS 有稀释作用. 在采样 I 区, 沿东南一西北中轴线方向, 湖泊 TDS 总体 呈现东南低、西北高的趋势. 在采样 II 区, 4 月 TDS 由西北向东南呈增加趋势, 而 9 月呈现中间低、两端高的 趋势. 通过对 9 月和 4 月采样点离子浓度平均值进行统计 (表 1), 可以看出其 9 月各离子浓度的平均值都高 于 4 月, $\mathrm{Na}^{+}$和 $\mathrm{Cl}^{-}$浓度最高, $\mathrm{Mg}^{2+}$ 和 $\mathrm{Ca}^{2+}$ 浓度最低, 最高值和最低值相差 4 个数量级. 通过对各个离子以及 TDS 之间相关系数的计算, 发现 $\mathrm{Na}^{+}$和 $\mathrm{Cl}^{-} 、 \mathrm{Na}^{+}$和 TDS、 $\mathrm{Cl}^{-}$和 TDS 这 3 组的相关系数最高, 9 月和 4 月其值并 没有发生变化, 分别为 $0.98 、 0.92$ 和 0.89 .9 月和 TDS 相关系数最低的是 $\mathrm{Ca}^{2+}$, 为 $0.08,4$ 月和 TDS 相关系数 最低的为 $\mathrm{Mg}^{2+}$, 为 0.08 . 另外, 不论是 4 月还是 9 月, $\mathrm{K}^{+} 、 \mathrm{SO}_{4}^{2-} 、 \mathrm{CO}_{3}^{2-}$ 和 $\mathrm{TDS}$ 的相关系数都小于 0.85 , 大于 $0.50 . \mathrm{HCO}_{3}^{-}$和 TDS 的相关系数在 0.23 左右. 

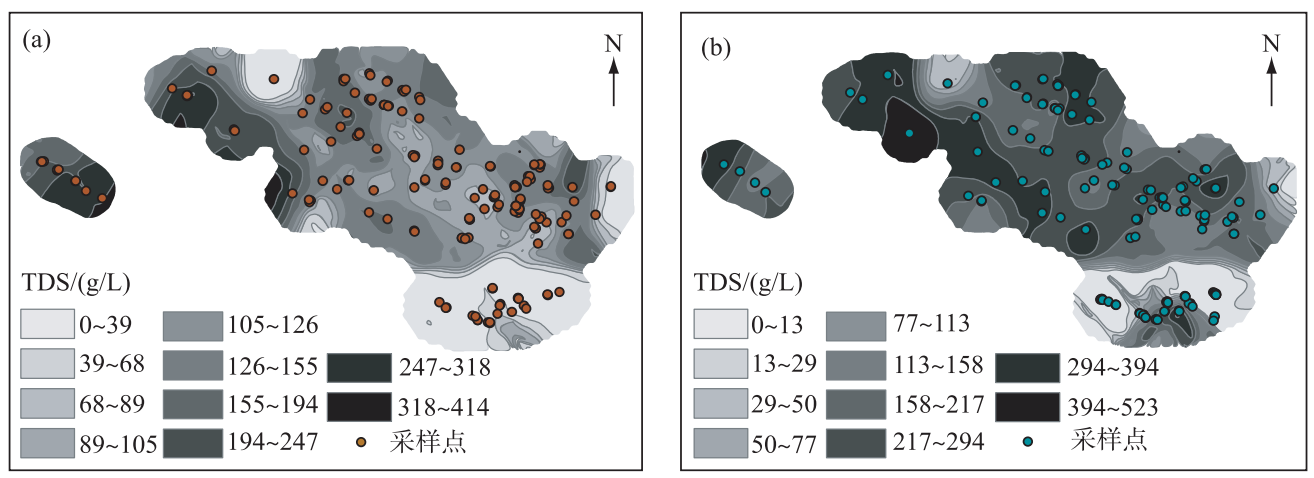

图 2 采样点分布和 TDS 空间插值图: (a) 4 月采样点; (b) 9 月采样点

Fig.2 Distribution of sampling sites and spatial interpolation graph of TDS:

The interpolation results in April (a) and September (b)

表 1 采样点离子浓度平均值

Tab.1 Average ion concentration of all sampling sites

\begin{tabular}{cccccccccc}
\hline \multirow{2}{*}{ 时间 } & \multicolumn{7}{c}{ 平均离子浓度/ $(\mathrm{g} / \mathrm{L})$} \\
\cline { 2 - 9 } & $\mathrm{Na}^{+}$ & $\mathrm{K}^{+}$ & $\mathrm{Mg}^{2+}$ & $\mathrm{Ca}^{2+}$ & $\mathrm{Cl}^{-}$ & $\mathrm{SO}_{4}^{2-}$ & $\mathrm{CO}_{3}^{2-}$ & $\mathrm{HCO}_{3}^{-}$ \\
\hline 4 月 & 41.93 & 3.67 & 0.51 & 0.48 & 44.94 & 12.56 & 15.24 & 2.35 \\
9 月 & 68.76 & 6.37 & 0.52 & 1.00 & 59.15 & 24.57 & 23.96 & 3.97 \\
\hline
\end{tabular}

\subsection{4 月各离子浓度空间分布的复杂性分析}

由于离子浓度受补给来源、水文地质等多种因素的影响, 其变化具有复杂性. 而样本熵是测度复杂性的有 力工具, 它不仅可以将复杂性进行量化, 与滑动窗口相结合还可以很好地检测突变. 为了便于观察各个离子复 杂性随空间的变化趋势, 对 4 月各采样点进行西北一东南方向排列, 其原因为: 首先, 采样点分布是呈现西北一 东南方向, 本文主要分析西北一东南方向各离子空间分布的复杂性; 其次, 经过大量排列试算, 采样点按其他任 何方向排列, 熵值空间分布趋势和西北一东南方向相差无几, 只是有一个小角度的偏移. 排列完以后对各离子 进行熵值计算, 最后对计算得到的结果进行普通克里金插值, 插值结果如图 3 所示, 插值误差见表 2 . 从图 3 可 以看出各个离子的熵值和 TDS 空间分布规律明显, 除 $\mathrm{Mg}^{2+} 、 \mathrm{SO}_{4}^{2-}$ 外, 其他离子熵值和 TDS 熵值都是西北和东 南角高、其他区域低; $\mathrm{Mg}^{2+}$ 熵值空间分布趋势和其他离子则刚好相反, 呈现中间高、两端低的趋势; $\mathrm{SO}_{4}^{2-}$ 熵值空 间分布规律在采样I区和东南角处与其他离子不一致; $\mathrm{Mg}^{2+}$ 熵值较低,且较低值区域面积大.

表 2 空间插值误差

Tab.2 Spatial interpolation error

\begin{tabular}{ccccccccccc}
\hline 时间 & 空间插值误差 & $\mathrm{TDS}$ & $\mathrm{Na}^{+}$ & $\mathrm{K}^{+}$ & $\mathrm{Mg}^{2+}$ & $\mathrm{Ca}^{2+}$ & $\mathrm{Cl}^{-}$ & $\mathrm{SO}_{4}^{2-}$ & $\mathrm{CO}_{3}^{2-}$ & $\mathrm{HCO}_{3}^{-}$ \\
\hline \multirow{2}{*}{4 月 } & 误差 & -0.001 & -0.003 & -0.004 & 0.001 & -0.004 & -0.005 & 0.000 & -0.004 & -0.007 \\
& 均方根误差 & 0.064 & 0.084 & 0.077 & 0.081 & 0.051 & 0.090 & 0.043 & 0.085 & 0.084 \\
& 标准均方根误差 & 0.960 & 0.836 & 1.156 & 1.433 & 0.864 & 1.099 & 1.122 & 1.061 & 0.969 \\
& 平均标准差 & 0.065 & 0.102 & 0.066 & 0.055 & 0.059 & 0.080 & 0.037 & 0.008 & 0.083 \\
9 & 月 误差 & -0.002 & -0.002 & -0.002 & 0.000 & -0.002 & -0.001 & 0.001 & 0.000 & -0.005 \\
& 均方根误差 & 0.056 & 0.050 & 0.048 & 0.013 & 0.150 & 0.055 & 0.034 & 0.047 & 0.031 \\
& 标准均方根误差 & 0.563 & 0.581 & 0.589 & 0.963 & 0.167 & 0.596 & 0.644 & 0.921 & 1.524 \\
& 平均标准差 & 0.105 & 0.089 & 0.079 & 0.013 & 0.067 & 0.095 & 0.063 & 0.048 & 0.025 \\
\hline
\end{tabular}



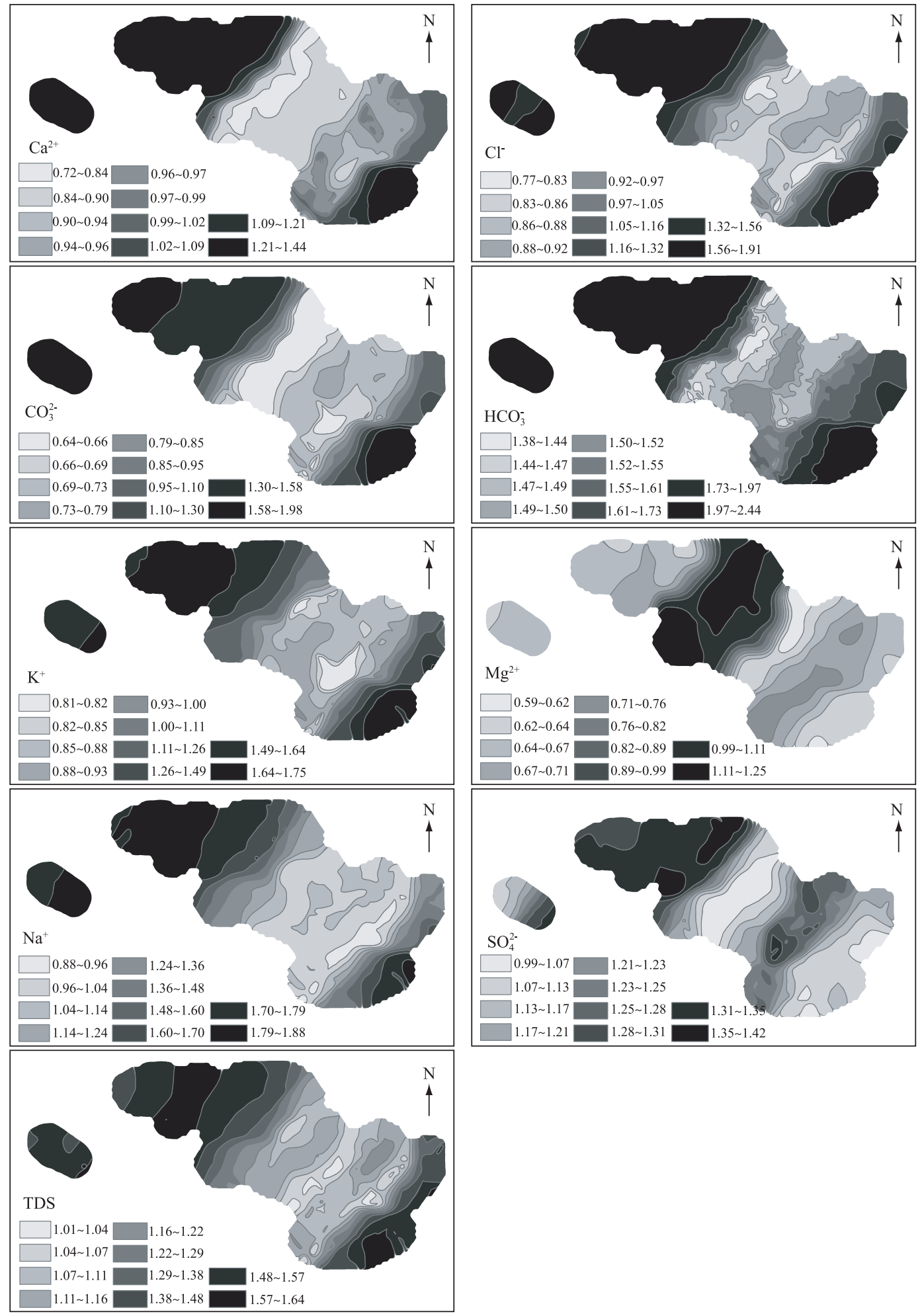

图 34 月各个离子和 TDS 复杂性的空间变化趋势(空白部分表示无值区)

Fig.3 Spatial complexity variation trend of each ion and TDS in April (The blank part indicates no value) 
熵值的空间分布规律取决于样本序列浓度值, 离子浓度序列空间分布越均匀、越有规律, 则其熵值越 小,而离子浓度序列的空间规律性强弱受水文地质环境、气候条件和水文地球化学环境等多种因素综合影 响. 本文主要从水源补给、气候条件和水文地球化学方面进行分析. 对于同一月份的采样点, 由于研究区较 小, 研究区内湖泊遍地分布, 地貌、植被等条件十分相似, 这样就极大降低了研究区内部区域气候条件的差 异, 使得地表有效辐射、气温、降水等对摘值影响十分有限. 气候条件十分相似的情况下, 离子熵值的空间分 布则主要受到水源补给和水文地球化学方面的影响.

水源补给方向不同, 水流经过矿物的顺序就不同, 这会造成水中溶解的矿物浓度和水化学类型的差 异 ${ }^{[37]}$. 主要离子 $\mathrm{Na}^{+} 、 \mathrm{~K}^{+} 、 \mathrm{Cl}^{-}$、和 $\mathrm{CO}_{3}^{2-}$ 的熵值空间分布 (除东南部外) 条带规律较为明显, 这种分布规律可能 受到水流补给方向的影响. 若不同的湖泊是从不同的方向进行补给, 则其补给水所携带的矿物浓度不同, 长 期日积月累, 则会造成不同湖泊之间离子浓度的巨大差异, 很难出现摘值的这种条带型分布. 东南部熵值条 带型空间分布规律不明显是因为存在一条无湖风蚀带——伊克力敖包, 该条带主要受褶皱隆起控制 ${ }^{[36,39]}$, 这对水流方向有很大的影响. 另外, 补给量的多少也会对熵值空间分布规律产生影响. $\mathrm{Cl}^{-} 、 \mathrm{~K}^{+} 、 \mathrm{Na}^{+} 、 \mathrm{CO}_{3}^{2-}$ 和 $\mathrm{HCO}_{3}^{-}$都是中间熵值较低, 西北和东南角离子熵值较高, 这种分布和补给量的多少有关. 根据热力学理论, 外 界能量的输人使得系统走向有序, 当外界能量输人作用减弱时, 耗散使得系统走向混乱或无序, 复杂度增 加, 从而使样本熵值增大 ${ }^{[40-41]}$. 中间部分水源补给较多, 其外界能量输人较多, 使离子浓度有序性增加, 从而 使复杂度降低, 样本摘值减小; 东南角湖泊 TDS 较小且夹杂几个 TDS 很高的湖泊, 相差高达 2 个数量级, 这 几个 TDS 较高的湖泊可能是因为东南地形等原因使其补给量很少, 其补给很可能来自于降水直接或间接补 给 ${ }^{[13,15-16]}$; 西北部湖泊 TDS 很高, 且相邻湖泊 TDS 值变化很大, 如 2010 年 9 月苏亥特吉林 TDS 为 $218.77 \mathrm{~g} / \mathrm{L}$, 诺尔图 (西) 为 $401.2 \mathrm{~g} / \mathrm{L}$, 高 TDS 湖泊之间偶尔会夹杂出现 TDS 为几十 $\mathrm{g} / \mathrm{L}$ 的湖泊, 可能是区域水文地质条 件等原因使得个别湖泊补给量高于周围湖泊,但整体补给量相对较少.

4 月, $\mathrm{Mg}^{2+} 、 \mathrm{SO}_{4}^{2-}$ 熵值空间分布和其他可溶性离子不一致 (相同地点进行比较, 排除水源补给影响) 的一 个主要原因是络合物和沉淀的产生. 通过用 PHREEQC 对水中各个矿物饱和指数 (SI) 进行计算. 从图 $5 \mathrm{a}$ 可 以看出, 除了在东南方向 $\mathrm{CaMg}\left(\mathrm{CO}_{3}\right)_{2}$ 和 $\mathrm{MgCO}_{3}$ 的饱和指数小于 0.2 以外, 其他区域饱和指数基本都大于 0.2 (对于离子浓度较高的离子一般认为大于 0.2 产生沉淀, 小于 -0.2 发生溶解 ${ }^{[37]}$ ), 说明 $\mathrm{Mg}^{2+}$ 发生了沉淀, 沉淀的产生对离子浓度序列产生影响, 进而使熵值的空间分布异于其他可溶性离子. 由于铁盐在地壳中分 布并不广泛 ${ }^{[42]}, \mathrm{Mg}^{2+}$ 浓度序列值都很低, 且变化不大, 造成其熵值空间分布整体较小. 对于 $\mathrm{SO}_{4}^{2-}$, 大部分采 样点饱和指数值都小于 0.2 , 但也有一部分采样点的饱和指数值处于 $-0.2 \sim 0.2$ 之间, 使 $\mathrm{SO}_{4}^{2-}$ 处在一个准均 衡状态, 既有沉淀又有溶解, 再加上西北区域沉淀的产生, 使 $\mathrm{SO}_{4}^{2-}$ 和其他离子摘值空间分布不一致. 另外, $\mathrm{SO}_{4}^{2-}$ 还会和其他阳离子生成 $\mathrm{CaSO}_{4}^{0}$ 和 $\mathrm{MgSO}_{4}^{0}$ 等络合物, 络合物的产生对 $\mathrm{SO}_{4}^{2-}$ 离子熵值空间分布也有一定 的影响 ${ }^{[37]}$.

4 月, $\mathrm{Na}^{+} 、 \mathrm{~K}^{+} 、 \mathrm{Cl}^{-}$熵值较为接近, 且熵值空间分布规律和 TDS 较相似, 这是因为 $\mathrm{Na}^{+} 、 \mathrm{~K}^{+} 、 \mathrm{Cl}^{-}$这几个可溶 性离子构成了 TDS 的主要成分, 其离子浓度变化和 TDS 的变化有正相关性. 通过对各个离子熵值平均值进 行统计 (表 3), 离子熵值由大到小依次为 $\mathrm{HCO}_{3}^{-} 、 \mathrm{Na}^{+} 、 \mathrm{SO}_{4}^{2-} 、 \mathrm{Cl}^{-} 、 \mathrm{~K}^{+} 、 \mathrm{Ca}^{2+} 、 \mathrm{CO}_{3}^{2-}$ 和 $\mathrm{Mg}^{2+}$. TDS 熵值和 $\mathrm{Na}^{+} 、 \mathrm{Cl}^{-} 、$ $\mathrm{K}^{+}$熵值相关系分别为 $0.93 、 0.92 、 0.94$.

\subsection{9 月各离子浓度空间分布的复杂性分析}

同样地,先对 9 月各采样点进行西北一东南方向排列, 再计算各离子浓度的熵值, 最后用得到的熵值进 行普通克里金插值, 插值结果见图 4, 插值误差见表 2. 从图 4 可以看出除 $\mathrm{SO}_{4}^{2-} 、 \mathrm{Ca}^{2+}$ 和 $\mathrm{Mg}^{2+}$ 以外, 其他 5 个离 子和 TDS 的熵值空间分布也是东南和西北角高、其他区域低; $\mathrm{SO}_{4}^{2-}$ 整体熵值较高, 整体变化趋势是中间低、 两端高, 中间有一条比周围熵值略高的条带. $\mathrm{Ca}^{2+}$ 和 $\mathrm{Mg}^{2+}$ 整体熵值较低, $\mathrm{Mg}^{2+}$ 商值两端低、中间高, $\mathrm{Ca}^{2+}$ 除了 在采样 I 区西北端熵值突然增大外, 其他区域熵值都很低; $\mathrm{HCO}_{3}^{-} 、 \mathrm{Na}^{+} 、 \mathrm{Cl}^{-} 、 \mathrm{~K}^{+}$和 $\mathrm{CO}_{3}^{2-}$ 熵值空间分布呈条带 状,变化趋势明显.

和 4 月相比, 9 月 $\mathrm{Ca}^{2+}$ 和 $\mathrm{SO}_{4}^{2-}$ 熵值空间分布规律差异较大 (其他离子熵值空间分布的解释参考 4 月). 通过饱和指数的计算, 无论 4 月还是 9 月,除在东南方向外, $\mathrm{CaCO}_{3}$ 饱和指数基本都大于 0.2 (图 5), 只有 9 月 $\mathrm{Ca}^{2+}$ 商值和其他可溶性离子熵值空间分布不一致,这可能与 $\mathrm{CO}_{2}$ 分压影响有关. $\mathrm{CO}_{2}$ 分压对 $\mathrm{CaCO}_{3}$ 溶解度的 


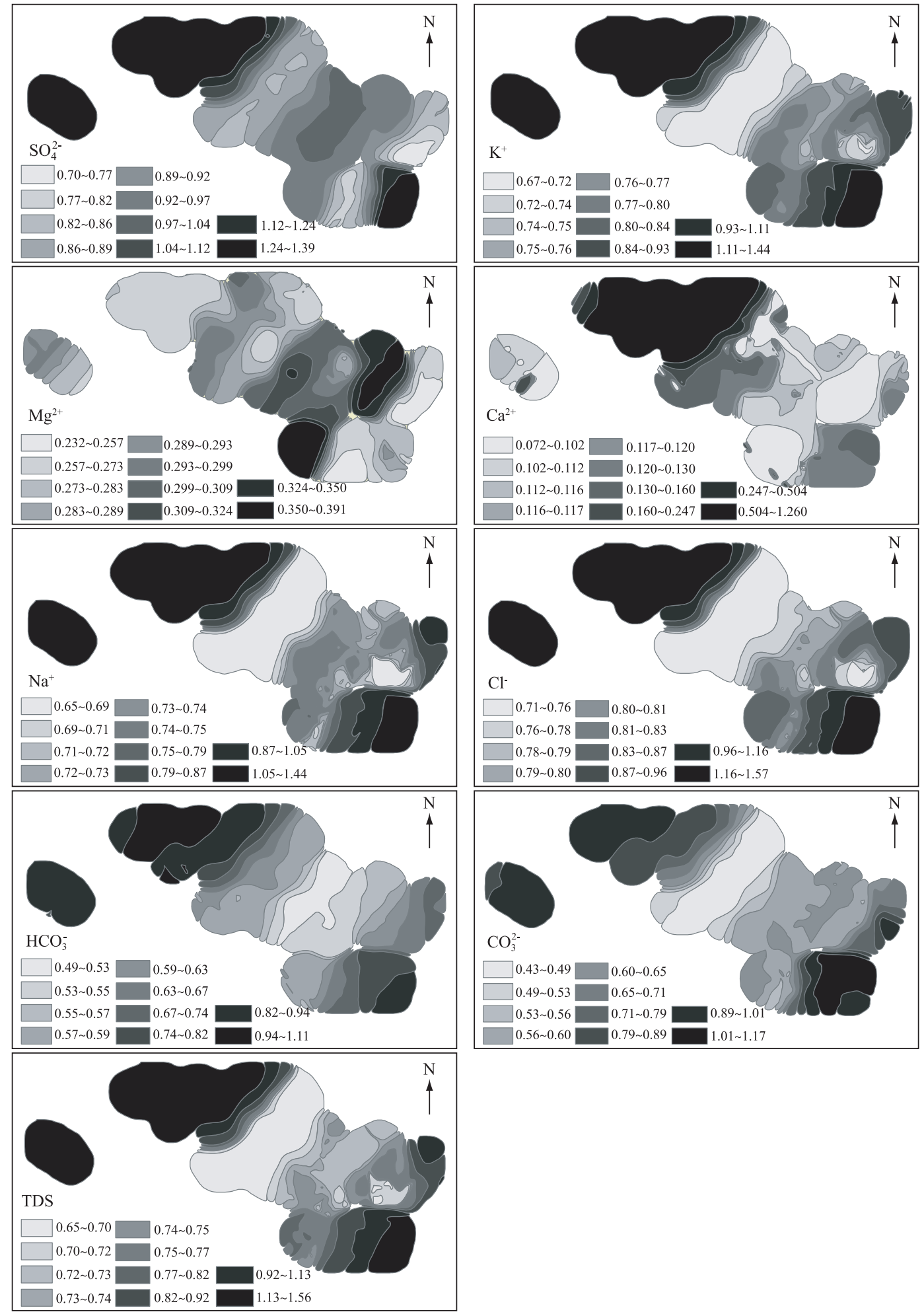

图 49 月各个离子和 TDS 空间复杂性变化趋势(空白部分表示无值区)

Fig.4 Spatial complexity variation trend of each ion and TDS in September(The blank part indicates no value) 
影响也很大 ${ }^{[37,43]}$. 本文在计算饱和指数时考虑了络合物和温度对矿物饱和指数的影响, 没有考虑 $\mathrm{CO}_{2}$ 分压 的影响. 4 月温度较低, $\mathrm{CO}_{2}$ 分压较大, 促进 $\mathrm{CaCO}_{3}$ 的溶解, 从而使 $\mathrm{Ca}^{2+}$ 和可溶性离子熵值空间分布的相似性 增加, 而 9 月则刚好相反. 另外, 随着 9 月 TDS 的增加, $\mathrm{Ca}^{2+}$ 相对含量迅速减小, 这是由于 $\mathrm{CaSO}_{4}$ 的溶解度有 限和 $\mathrm{CaCO}_{3}$ 溶解度低所致 ${ }^{[42]}$, 这会导致 $\mathrm{Ca}^{2+}$ 浓度序列值整体较低, 序列值变化幅度小, 整体熵值偏低. 影响 水中 $\mathrm{Ca}^{2+}$ 浓度的因素很多, 如 $\mathrm{pH}$ 值、 $\mathrm{CO}_{2}$ 分压、同离子效应、络合作用、盐度效应、地下矿物含量、离子吸附作 用和阳离子交换等,具体影响还需要在完善已有资料的基础上进行系统的水文地球化学模拟. 从图 $5 \mathrm{~b}$ 可以 看出, 相比于 4 月, 9 月石膏沉淀量增加, 中间部分有多个采样点饱和指数值处于 $-0.2 \sim 0.2$ 之间, 说明 $\mathrm{SO}_{4}^{2-}$ 在沉淀和溶解之间不停转化, 这增加了 $\mathrm{SO}_{4}^{2-}$ 的不规律性, 使其熵值整体较高, 这也可能是 $\mathrm{SO}_{4}^{2-}$ 在中间有一 条比周围熵值略高条带的原因.

9 月, $\mathrm{Na}^{+} 、 \mathrm{Cl}^{-} 、 \mathrm{~K}^{+}$熵值空间分布趋势几乎相同 (图 4), 其相关系数达到 0.99 , 且熵值空间分布规律和 TDS 较相似, 这同样是因为 $\mathrm{Na}^{+} 、 \mathrm{~K}^{+} 、 \mathrm{Cl}^{-}$这几个可溶性离子构成了 TDS 的主要成分, 其离子浓度变化和 TDS 的变化有正相关性. 通过对各个离子熵值的平均值进行统计 (表 3), 离子熵值由大到小依次为: $\mathrm{SO}_{4}^{2-} 、 \mathrm{Cl}^{-}$、 $\mathrm{K}^{+} 、 \mathrm{Na}^{+} 、 \mathrm{CO}_{3}^{2-} 、 \mathrm{HCO}_{3}^{-} 、 \mathrm{Mg}^{2+} 、 \mathrm{Ca}^{2+}$.

表 3 各个离子和 TDS 平均熵值

Tab.3 Average entropy values of each ion and TDS

\begin{tabular}{cccccccccc}
\hline \multirow{2}{*}{ 时间 } & \multicolumn{1}{c}{ 离子平均熵值 } \\
\cline { 2 - 10 } & $\mathrm{TDS}$ & $\mathrm{Na}^{+}$ & $\mathrm{K}^{+}$ & $\mathrm{Mg}^{2+}$ & $\mathrm{Ca}^{2+}$ & $\mathrm{Cl}^{-}$ & $\mathrm{SO}_{4}^{2-}$ & $\mathrm{CO}_{3}^{2-}$ & $\mathrm{HCO}_{3}^{-}$ \\
\hline \multirow{2}{*}{ 4月 } & 1.28 & 1.31 & 1.16 & 0.81 & 1.03 & 1.17 & 1.21 & 0.99 & 1.75 \\
9月 & 0.87 & 0.83 & 0.88 & 0.29 & 0.26 & 0.91 & 0.98 & 0.69 & 0.66 \\
\hline
\end{tabular}
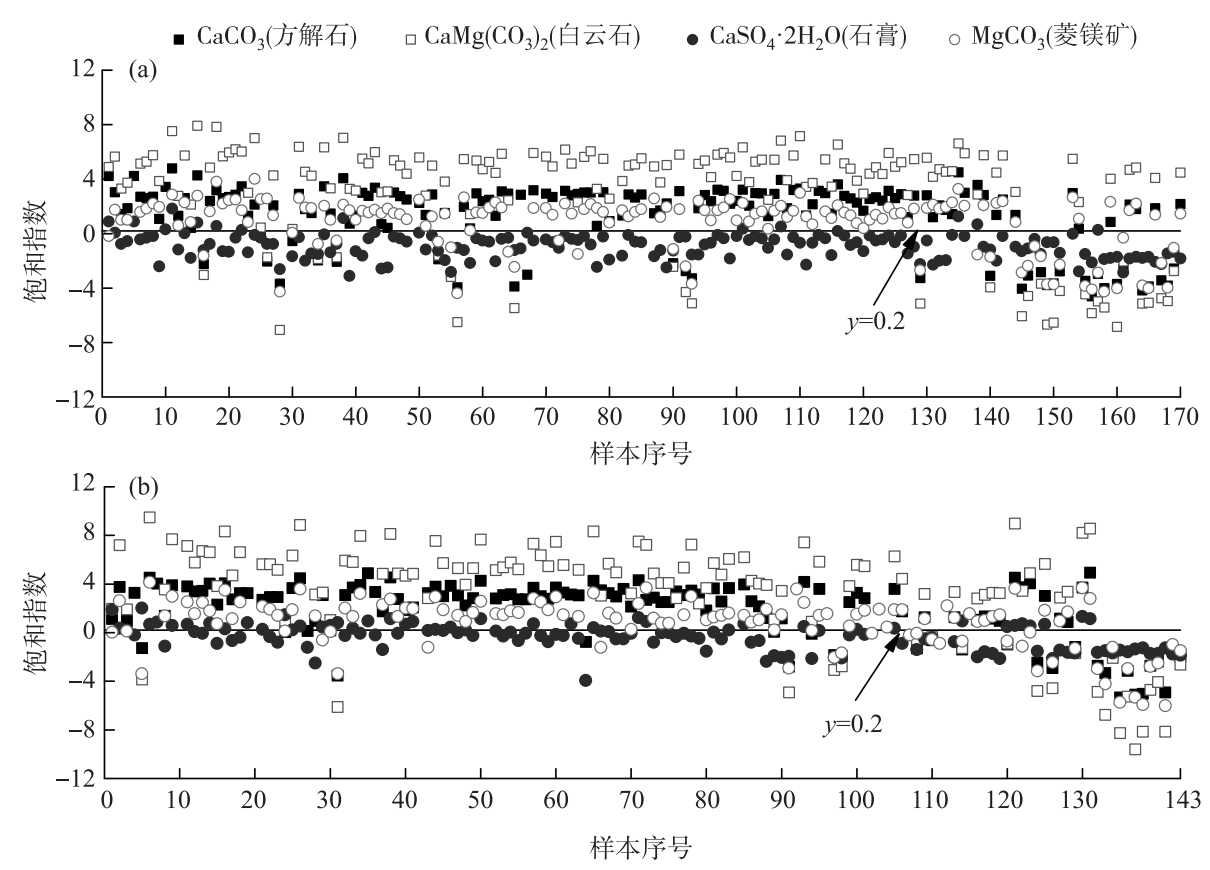

图 5 各采样点不同矿物的饱和指数:4 月采样点 (a);9 月采样点 (b)

(采样点样本序号呈西北一东南方向排列)

Fig.5 Saturation index of different minerals at each sampling site: The sampling sites in April (a); The sampling sites in September (b) (The sampling sites are numbered in the northwest-southeast direction) 


\section{4 对比分析和讨论}

通过图 3、4 对比, 发现 4 月各个离子和 TDS 的熵值都高于 9 月 (表 3), 且高熵值区域面积 (图中黑色部 分) 也是 4 月大于 9 月; 9 月和 4 月 $\mathrm{Na}^{+} 、 \mathrm{Cl}^{-} 、 \mathrm{~K}^{+} 、 \mathrm{CO}_{3}^{2-} 、 \mathrm{HCO}_{3}^{-}$熵值都是西北和东南角高, 其他区域低; $\mathrm{Mg}^{2+}$ 则 是中间部分离子熵值较高、其他区域低; $\mathrm{Ca}^{2+}$ 商值在 4 月和 9 月相差很大, 且其空间分布趋势也大不相同, 4 月 $\mathrm{Ca}^{2+}$ 熵值在西北和东南角高, 其他区域低, 到了 9 月, $\mathrm{Ca}^{2+}$ 商值在采样 I 区西北部陡然增加, 有一个熵值突 变区间,之后熵值又变的很低; $\mathrm{SO}_{4}^{2-}$ 摘值空间分布趋势在 4 月和 9 月基本相同, 不同的是东南角有无较高摘 值的出现.

由样本熵的性质可知, 熵值越高, 序列的自我相似性越低, 其分布就越不规律, 序列越复杂. 无论 9 月还 是 4 月, $\mathrm{Na}^{+} 、 \mathrm{Cl}^{-} 、 \mathrm{~K}^{+} 、 \mathrm{CO}_{3}^{2-} 、 \mathrm{HCO}_{3}^{-}$都是中间部分离子浓度自我相似性高, 分布相对规律, 差异性较小, 在西北 部和东南角离子浓度自我相似性低,分布不规律,差异性较大,而 $\mathrm{Mg}^{2+}$ 则呈现相反的空间分布规律. $\mathrm{SO}_{4}^{2-}$ 熵 值空间分布趋势在 4 月和 9 月基本相同,不同的是 4 月东南角规律性基本和中间部分一致,而 9 月东南角离 子浓度变化比中间部分更不规律. 4 月 $\mathrm{Ca}^{2+}$ 熵值在西北和东南角高, 其他区域相对较低,到了 9 月,在采样 I 区西北部有一个突变区间,该区间内离子浓度变化很不规律, 区间以外则十分规律.

对于不同月份的采样点,其熵值受气候条件影响较大. 由表 3 可知, 4 月各个离子和 TDS 的平均熵值都 要大于 9 月, 从图 3 和图 4 也可以看出 9 月熵值空间分布规律比 4 月更加明显, 低熵值区域面积比 4 月大, 这是因为 9 月沙漠地表有效辐射、气温 ${ }^{[44]}$ 和降水 ${ }^{[35]}$ 等都要高于 4 月. 同样根据热力学理论 ${ }^{[40-41]}, 9$ 月外界能 量的输人大于 4 月, 使得系统更加有序, 复杂度相对较低, 熵值较小. 虽然 4 月湖泊补给量要大于 9 月, 增加 了外界能量的输人, 使熵值差距缩小, 但其熵值仍大于 9 月, 可见气候条件是熵值季节性变化的一个主导 因素.

对于湖泊补给源的宏观流向, 不同学者有不同的观点, 主要有以下几种: 从东南雅布赖山或当地降水人 渗后向西北方向流动 ${ }^{[4,13-18]}$; 黑河在金塔一鼎新盆地渗漏产生的水或祁连山融水自西向东流动或顺着阿尔金 断裂自西向东流动后再沿古日乃断层自东南向西北流动 ${ }^{[22-25]}$; 来自西南、东北和东南方向的补给水向沙漠 腹地汇集再流向西北 ${ }^{[45]}$; 沿 NNE 断层方向流动 ${ }^{[3]}$. 但我们认为从东南向西北流动的可能性较大, 主要有以 下原因: (1) 东南地势高, 西北地势低, 为水源输送提供动力条件; (2) 从图 1 可以看出, TDS 有从东南到西北 逐渐增大的趋势, 其他方向 TDS 则无明显增大或减小趋势; (3) 用手持 GPS 得到数据和前人用卫星数据或 实测数据得到的湖泊水位和地下水水位都是东南高西北低 ${ }^{[21,27,45]}$; (4) 根据 $1950 \mathrm{~s}-1960 \mathrm{~s}$ 地质部门在内蒙 古西部展开的 1:50 万区域综合地质一水文地质普查, 认为巴丹吉林沙漠地下水总体向西北方向流动; (5) 在 $1970 \mathrm{~s}-1980 \mathrm{~s}$, 在阿拉善盟局部地区进行的 $1: 20$ 万区域水文地质报告中地质人员发现巴丹吉林沙漠地下水 由雅布赖地区向沙漠腹地倾斜, 支持地下水向西北流动的观点; (6) 从熵值条带分布来看, 其很有可能是受 东南一西北方向水流方向的影响. 对于研究区内条带型空间分布规律, 有学者猜测可能受气候条件的影 ${ }^{\text {响 }}{ }^{[16]}$, 但在这么小的研究区域范围内, 同一时间不同区域之间气候差异影响十分有限, 且在 9 月和 4 月气候 条件相差很大的情况下, 对可溶性离子而言, 这种条带始终存在, 可见气候条件并不能改变摘值条带型空间 分布规律, 其原因很可能是水流经过不同矿物时所溶解的矿物含量不同, 补给湖泊后不断累积, 造成沿东南 一西北方向熵值的条带型空间分布规律. 基于以上,本文认为补给源自西向东或沿 NEE 方向流动的可能性 不大, 虽然从结果来看, 水流有顺着阿尔金断裂自西向东补给后再沿古日乃断层自东南向西北流动的可能 性, 但有学者认为其地质依据不足 ${ }^{[9,17]}$, 即便有断层其导水性也很值得怀疑, 这种水流补给方式存在可能性 很小.

综合前面的分析, 对于离子熵值的季节性变化,气候条件是主导因素. 在同月份气候条件十分相似的情 况下, 对可溶性离子而言, 影响其熵值空间变化的主要因素是水源补给. 熵值的条带型空间分布规律则很可 能受水流补给方向的影响, 无论 4 月还是 9 月, 可溶性离子熵值都是中间低、两端高, 说明中间部分水源补给 量相对较大. $\mathrm{SO}_{4}^{2-} 、 \mathrm{Ca}^{2+} 、 \mathrm{Mg}^{2+}$ 其熵值空间分布规律和其他可溶性离子不一致, 这主要是因为水文地球化学方

(1) 地质部水文地质工程地质局第一大队. 内蒙古高原西部综合地质一水文地质普查报告书 ( $1: 50$ 万), 1961 .

(2) 中国人民解放军 00929 部队. 中华人民共和国区域水文地质普查报告 (1:20 万) 雅布赖盐场幅, 1982. 
面的影响, 如络合物和沉淀的产生,但具体如何影响,还需在完善已有资料的基础上进行系统的模拟研究. 对于湖泊补给源的宏观流场,则认为自东南向西北流动的可能性较大.

\section{4 结论}

本研究利用样本熵方法, 对巴丹吉林沙漠湖泊水离子的熵值进行空间插值, 从复杂性角度探讨湖泊水 离子浓度和 TDS 的空间变化规律, 同时对 9 月和 4 月湖泊水离子和 TDS 的空间复杂性变化进行对比分析, 可以为湖泊水化学空间分布特征、湖泊演变、湖泊水补给来源等问题的研究提供一定的参考和依据. 本研究 的主要结论为:

1) 在巴丹吉林沙漠东南湖泊群中, 4 月各个离子和 TDS 的熵值都要高于 9 月,4月与 9 月相比, 各个离 子的浓度和 TDS 值的自我相似性低、空间复杂性高、规律性不明显.

2) 不论 4 月还是 9 月, TDS 的熵值和 $\mathrm{Na}^{+} 、 \mathrm{Cl}^{-} 、 \mathrm{~K}^{+}$离子的熵值相关系数均较高, TDS 和 $\mathrm{Na}^{+} 、 \mathrm{Cl}^{-} 、 \mathrm{~K}^{+}$在空 间上的复杂性变化趋势较为一致; $\mathrm{Na}^{+} 、 \mathrm{Cl}^{-} 、 \mathrm{~K}^{+} 、 \mathrm{CO}_{3}^{2-} 、 \mathrm{HCO}_{3}^{-}$都是在西北部和东南角离子熵值高, 离子浓度相 似性低,空间分布复杂、无规律, 中间部分离子熵值较低,空间分布有较好的规律性.

$3) \mathrm{Mg}^{2+}$ 离子熵值比同月份其他离子低, 复杂性较高的区域都是在采样 I 区中间部分. $\mathrm{SO}_{4}^{2-}$ 离子的熵值 空间分布趋势在 4 月和 9 月基本相同, 不同的是东南角有无较高熵值的出现. 4 月 $\mathrm{Ca}^{2+}$ 离子熵值在西北部和 东南角复杂度高, 其他区域相对较低, 9 月在采样 I 区西北部有一个突变区间, 该区间内离子浓度变化很不 规律, 区间以外,变化则十分规律.

4) 对于离子熵值的季节性变化, 气候条件是主导因素. 在同月份气候条件十分相似的情况下, 对可溶性 离子而言, 影响其熵值空间变化的主要因素是水源补给. 无论 4 月还是 9 月, 可溶性离子熵值在研究区中间 部分较低,说明该区域水源补给量较大.

\section{5 参考文献}

[ 1 ] Dong GR, Chen HZ. Desert, sandy land evolution and climate change in North China since 150ka. Sci China: Ser B, 1995, 25(12) : 1303-1312. DOI: 10.1360/zb1995-25-12-1303. [董光荣, 陈惠忠. 150 ka 以来中国北方沙漠、沙地演 化和气候变化. 中国科学: B 辑, 1995, 25(12): 1303-1312.]

[ 2 ] Chen JS, Li L, Wang JY et al. Water resources : groundwater maintains dune landscape. Nature, 2004, 432 (7016) : 459460. DOI: $10.1038 / 432459$ a.

[ 3 ] Chen JS, Zhao X, Sheng XF et al. Research on formation mechanism of megadunes and lakes in the Badain Jaran Desert. Chin Sci Bull, 2006, 51(23) : 2789-2796. [ 陈建生, 赵霞, 盛雪芬等. 巴丹吉林沙漠湖泊群与沙山形成机理研究. 科学通报, 2006, 51(23): 2789-2796.]

[ 4 ] Yang XP. Water chemistry of the lakes in the Badain Jaran Desert and their Holocene evolutions. Quat Sci, 2002, 22(2): 97-104. [杨小平. 巴丹吉林沙漠腹地湖泊的水化学特征及其全新世以来的演变. 第四纪研究, 2002, 22(2) : 97-104.]

[ 5 ] Yang X. Landscape evolution and precipitation changes in the Badain Jaran Desert during the last 30000 years. Chin Sci Bull, 2000, 45(11) : 1042-1047. DOI: 10.1007/bf02884988.

[ 6 ] Dong ZB, Wang T, Wang XM. Geomorphology of the megadunes in the Badain Jaran Desert. Geomorphology, 2004, 60 (1) : 191-203. DOI: 10.1016/j.geomorph.2003.07.023.

[ 7 ] Dong ZB, Qian G, Luo W et al. Geomorphological hierarchies for complex megadunes and their implications for mega-dune evolution in the Badain Jaran Desert. Geomorphology, 2009, 106(3) : 180-185. DOI: 10.1016/j.geomorph.2008.10.015.

[ 8 ] Yan MC, Wang GQ, Dong GR et al. Study on mega-dunes development and environmental change in Badain Jaran Desert. $J$ Desert Res, 2001, 21(4) : 361-366. [间满存, 王光谦, 董光荣等. 巴丹吉林沙漠沙山发育与环境演变研究. 中国 沙漠, 2001, 21(4): 361-366.]

[ 9 ] Zhang HC, Min QZ. Hydrology and lake evolution in hyperarid northwestern China and the mystery of megadunes formation in Badain Jaran Desert. Adv Earth Sci, 2006, 21(5): 532-538. [张虎才, 明庆忠. 中国西北极端干旱区水文与湖泊 演化及其巴丹吉林沙漠大型沙丘的形成. 地球科学进展, 2006, 21(5): 532-538.]

[10] Zhao JB, Shao TJ, Lv XH et al. The study on $\mathrm{CO}_{2}$ concentration and the diurnal variation laws of the highest megadune in 
Badain Jaran Desert. Geogr Res, 2010, 29(11) : 1994-2005. DOI: 10.11821/yj2010110008. [赵景波, 邵天杰, 吕晓虎 等. 巴丹吉林最高沙山区 $\mathrm{CO}_{2}$ 浓度与昼夜变化规律. 地理研究, 2010, 29(11) : 1994-2005.]

[11 Z Zhu ZD , Wu Z, Liu S et al eds. An outline of Chinese deserts. Beijing: Science Press, 1980: 16-19. [ 朱震达, 吴正, 刘恕. 中国沙漠概论. 北京: 科学出版社, 1980: 16-19.]

[12] Ma SH, Li ZL, Wang NA et al. Mineralogical assemblages in surface sediments and its formation mechanism in the groundwater recharged lakes: a case study of lakes in the Badain Jaran Desert. J Lake Sci, 2015, 27 (4) : 727-734. DOI: 10. 18307/2015.0422. [马素辉, 李卓仑, 王乃昂等. 地下水补给型湖泊表层沉积物矿物组成及其形成机制一一巴 丹吉林沙漠湖泊群为例. 湖泊科学, 2015, 27(4): 727-734.]

[13] Ma JZ, Chen FH, Zhao H. Change on climate change and groundwater recharge from the geochemical records of unsaturated zone in the Badain Jaran Desert in the recent 1000 years. Chin Sci Bull, 2004, 49(1) : 22-26. DOI: 10. 1360/ csb2004-49-1-22. [马金珠, 陈发虎, 赵华. 1000 年以来巴丹吉林沙漠地下水补给与气候变化的包气带地球化学记 录. 科学通报, 2004, 49(1) : 22-26.]

[14] Yang X, Williams MAJ. The ion chemistry of lakes and late Holocene desiccation in the Badain Jaran Desert, Inner Mongolia, China. Catena, 2003, 51(1) : 45-60. DOI: 10.1016/S0341-8162(02)00088-7.

[15] Ma NN, Yang XP. Environmental isotopes and water chemistery in the Badain Jaran Desert and in its southeastern adjacent areas, Inner Mongolia and their hydrological implications. Quat Sci, 2008, 28(4) : 702-711. [马妮娜, 杨小平. 巴丹吉 林沙漠及其东南边缘地区水化学和环境同位素特征及其水文学意义. 第四纪研究, 2008, 28(4): 702-711.]

[16] Lu Y, Wang NA, Li GP et al. Spatial distribution of lakes hydro-chemical types in Badain Jaran Desert. J Lake Sci, 2010, 22(5) : 774-782. DOI: 10.18307/2010.0521. [陆莹, 王乃昂, 李贵鹏等. 巴丹吉林沙漠湖泊水化学空间分布特征. 湖泊科学, 2010, 22(5): 774-782.]

[17] Zhao JB, Ma YD, Luo XQ et al. The discovery of surface runoff in the megadunes of Badain Jaran Desert, China, and its significance. Sci Chin Ear Sci, 2017, 47 (4) : 461-472. DOI: 10.1007/s11430-016-9019-2. [赵景波, 马延东, 罗小庆 等. 巴丹吉林沙漠沙山表层径流的发现及其指示意义. 中国科学: 地球科学, 2017, 47(4) : 461-472.]

[18] Wang XS, Hu XN, Jin XM et al. Interactions between groundwater and lakes in Badain Jaran Desert. Geosci Front, 2014, 21 (4) : 91-99. DOI: 10.13745/j.esf.2014.04.010. [王旭升, 胡晓农, 金晓媚等. 巴丹吉林沙漠地下水与湖泊的相互 作用. 地学前缘, 2014, 21(4): 91-99.]

[19] Edmunds W, Ma J, Aeschbach-Hertig W et al. Groundwater recharge history and hydrogeochemical evolution in the Minqin Basin, North West China. Appl Geochem, 2006, 21(12) : 2148-2170. DOI: 10.1016/j.apgeochem.2006.07.016.

[20] Ma J, Edmunds WM. Groundwater and lake evolution in the Badain Jaran Desert ecosystem, Inner Mongolia. Hydrogeol J, 2006, 14(7) : 1231-1243. DOI: 10.1007/s10040-006-0045-0.

[21] Gates JB, Edmunds WM, Darling WG et al. Conceptual model of recharge to southeastern Badain Jaran Desert groundwater and lakes from environmental tracers. Appl Geochem, 2008, 23 (12): 3519-3534. DOI: 10.1016/j. apgeochem. 2008. 07.019 .

[22] Chen JS, Fan ZC, Wang JY et al. Isotope methods for studying the replenishment of the lakes and downstream groundwater in the Badain Jaran Desert. Acta Geoscientica Si, 2003, 24(6): 497-504. [ 陈建生, 凡哲超, 汪集旸等. 巴丹吉林沙漠 湖泊及其下游地下水同位素分析. 地球学报, 2003, 24(6): 497-504.]

[23] Wang XJ, Chen JS, Xu BT. Application of the method of water chemical composition clustering to the analysis on recharge sources of groundwater in Badain Jaran Desert and Its Adjoining Regions. Geotech Invest Survey, 2005, (5) : 25-29. [王新 建, 陈建生, 许宝田. 水化学成分聚类法分析巴丹吉林沙漠及邻区地下水补给源. 工程勘察, 2005, (5) : 25-29.]

[24] Liu JG. Recharge mechanisms of lakes and groundwater in Badain Jaran Desert. Water Resour Prot, 2010, 26(2) : 18-23. [刘建刚. 巴丹吉林沙漠湖泊和地下水补给机制. 水资源保护, 2010, 26(2)：18-23.]

[25] Ding HW, Wang GL. Study on the formation mechanism of the lakes in the Badain Jaran Desert. Arid Zone Res, 2007,24 (1) : 1-7. DOI: 10.13866/j. azr.2007.01.001. [丁宏伟, 王贵玲.巴丹吉林沙漠湖泊形成的机理分析. 干旱区研究, $2007,24(1): 1-7$.

[26] Ma N, Wang NA, Zhu JF et al. Climate change around the Badain Jaran Desert in Recent 50 years. J Desert Res, 2011, 31(6) : 1541-1547. [马宁, 王乃昂, 朱金峰等. 巴丹吉林沙漠周边地区近 $50 \mathrm{a}$ 来气候变化特征. 中国沙漠, 2011, 31 (6) : 1541-1547.]

[27] Jiao JJ, Zhang X, Wang X. Satellite-based estimates of groundwater depletion in the Badain Jaran Desert, China. Sci Rep, 
2015, 5: 8960-8960. DOI: 10.1038/srep08960.

[28] Chou CM. Complexity analysis of rainfall and runoff time series based on sample entropy in different temporal scales. Stoch Env Res Risk A, 2014, 28(6) : 1401-1408. DOI: 10.1007/s00477-014-0859-6.

[29] Alcaraz R, Rieta J. A novel application of sample entropy to the electrocardiogram of atrial fibrillation. Nonlinear Analysis : Real World Appl, 2010, 11(2) : 1026-1035. DOI: 10.1016/j.nonrwa.2009.01.047.

[30] Richman JS, Moorman JR. Physiological time-series analysis using approximate entropy and sample entropy. Am J Physiol Heart Circ Physiol, 2000, 278(6) : H2039-H2049.

[31] Sun YH, Jou HL, Wu JC. Auxiliary diagnosis method for lead-acid battery health based on sample entropy. Energ Convers Manage, 2009, 50(9) : 2250-2256. DOI: 10.1016/j.enconman.2009.05.001.

[32] Zhu JF, Wang NA, Chen HB et al. Study on the boundary and the area of Badain Jaran Desert based on remote sensing imagery. Prog Geo, 2010, 29(9) : 1087-1094. DOI: 10.11820/dlkxjz.2010.09.010. [朱金峰, 王乃昂, 陈红宝等. 基 于遥感的巴丹吉林沙漠范围与面积分析. 地理科学进展, 2010, 29(9) : 1087-1094.]

[33] Qu JJ, Chang XL, Dong GR et al. Fractal behavior of Aeolian Sand Landform in typical megadune area of Badain Jaran Desert. J Desert Res, 2003, 23(4) : 361-365. [屈建军, 常学礼, 董光荣等. 巴丹吉林沙漠高大沙山典型区风沙地貌 的分形特性. 中国沙漠, 2003, 23(4): 361-365.]

[34] Dong Z, Qian G, Lv P et al. Investigation of the sand sea with the tallest dunes on Earth: China's Badain Jaran Sand Sea. Earth-Sci Rev, 2013, 120: 20-39. DOI: 10.1016/j.earscirev.2013.02.003.

[35] Wang NA, Ma N, Chen HB et al. A preliminary study of precipitation characteristics in the hinterland of Badain Jaran desert. Adv Water Sci, 2013, 24(2) : 153-160. [王乃昂, 马宁, 陈红宝等. 巴丹吉林沙漠腹地降水特征的初步分析. 水 科学进展, 2013, 24(2): 153-160.]

[36] Ma JZ, Huang TM, Ding ZY et al. Environmental isotopes as the indicators of the groundwater recharge in the south Badain Jaran Desert. Adv Earth Sci, 2007, 22(9) : 922-930. [马金珠, 黄天明, 丁贞玉等. 同位素指示的巴丹吉林沙漠南缘 地下水补给来源. 地球科学进展, 2007, 22(9) : 922-930.]

[37] Shen ZL, Zhu WH, Zhong ZS eds. Hydrogeochemistry foundation. Beijing: Geology Publishing House, 1993 : 26-59, 86108. [沈照理, 朱宛华, 钟佐笨. 水文地球化学基础. 北京: 地质出版社, 1993: 26-59, 86-108.]

[38] Bai DM, Qiu TS, Li XB. The sample entropy and its application in EEG based epilepsy detection. J Biomed Eng, 2007, 24(1) : 200-205. [白冬梅, 邱天爽, 李小兵. 样本熵及在脑电癫㾁检测中的应用. 生物医学工程学杂志, 2007, 24 (1) : 200-205.]

[39] Tan JA. The region types of the Alashan desert in Inner Mongolia. Geol Clct, 1964, (8) : 1-31. [谭见安. 内蒙古阿拉善 荒漠的地方类型. 地理集刊, 1964, (8): 1-31.]

[40] Li XG, Wang XL, Wei X. Multi-dimension characteristics of runoff complexity in the Jinghe Watershed. J Lanzhou Univ: Nat Sci, 2015, 51(4) : 447-453. [李勋贵, 王晓磊, 魏霞. 泾河流域径流复杂度的多维特性. 兰州大学学报: 自然 科学版, $2015, \mathbf{5 1}(4): 447-453$. ]

[41] Li X, Wei N, Wei X. Complexity analysis of precipitation-runoff series based on a new parameter optimization method of entropy. J Hydrol Eng, 2017, 22(9) : 04017029: 1-10. DOI: 10.1061/( ASCE) HE.1943-5584.0001554.

[42] Li XL, Sun ZX, Liu JH eds. Hydrogeochemistry. Beijing: Atomic Energy Press, 1988: 25-30. [李学礼, 孙占学, 刘金 辉. 水文地球化学. 北京: 原子能出版社, 1988: 25-30.]

[43] Qian H, Ma ZY, Li PY eds. Hydrogeochemistry. Beijing: Geology Publishing House, 2005: 50-58. [钱会, 马致远, 李 培月. 水文地球化学. 北京: 地质出版社, 2005: 50-58.]

[44] Ji GL, Zou JL. The seasonal variation of solar radiation budget over oases and desert in arid region. Plat Meteorol, 1994, 13(3) : 323-329. [季国良, 邹基玲. 干旱地区绿洲和沙漠辐射收支的季节变化. 高原气象, 1994, 13 ( 3 ): 323-329.]

[45] Zhang J, Wang XS, Hu XN et al. The macro-characteristics of groundwater flow in the Badian Jaran Desert. J Desert Res, 2015, 35(3) : 774-782. [张竞, 王旭升, 胡晓农等. 巴丹吉林沙漠地下水流场的宏观特征. 中国沙漠, 2015, 35 (3) : 774-782.] 